\title{
Identifikasi Kontaminasi Logam Berat pada Ayam Kuning Sukabumi di Bogor Utara
}

\section{Identification of Heavy Metal Contamination on Ayam Kuning Sukabumi in North Bogor}

\author{
D. R. Megabuana ${ }^{1}$, Z. Wulandari ${ }^{1 *}$, dan P. Rahayu ${ }^{2}$ \\ ${ }^{1}$ Departemen Ilmu Produksi dan Teknologi Peternakan, Fakultas Peternakan, Institut Pertanian Bogor, \\ Bogor - Indonesia \\ ${ }^{2}$ Balai Pengujian Mutu dan Sertifikasi Produk Hewan Bogor - Indonesia \\ *Corresponding E-mail: zakiahwulandari75@gmail.com \\ (Diterima: 14 November 2019; Disetujui: 10 Januari 2020)
}

\begin{abstract}
ABSTRAK
Ayam kuning sukabumi adalah salah satu pangan hewani yang banyak dijual di pinggir jalan. Tujuan penelitian ini adalah menganalisis pengaruh lama penjualan terhadap kadar kontaminasi logam berat $\mathrm{Pb}, \mathrm{Cd}$ dan $\mathrm{Cu}$ pada ayam kuning sukabumi di Kecamatan Bogor Utara. Perlakuan pada penelitian ini adalah waktu penjualan ayam kuning sukabumi yakni 0 jam dan 3 jam. Hasil menunjukkan bahwa terjadi peningkatan nilai rataan kadar $\mathrm{Pb}$ sebesar $112 \%$ dan Cd sebesar $55 \%$ pada ayam kuning sukabumi akibat lama penjualan selama tiga jam.
\end{abstract}

Kata kunci: Ayam Kuning Sukabumi, Bogor Utara, kontaminasi logam berat

\section{ABSTRACT}

Ayam Kuning Sukabumi is one of the animal foods that are sold on the streets. The purpose of this research was to analyze the content of $\mathrm{Pb}, \mathrm{Cd}$, and $\mathrm{Cu}$ on Ayam Kuning Sukabumi in the sub-district of North Bogor. Samples of Ayam Kuning Sukabumi were taken twice a day, i.e. when momentarily after being peddled, 0 and 3 hours. Results showed that an increase in the average value of $112 \%$ content of $\mathrm{Pb}$ and Cd by 55\% in Ayam Kuning Sukabumi was influenced by peddler for three hours.

Keywords: Ayam Kuning Sukabumi, North Bogor, heavy metal contamination

\section{PENDAHULUAN}

Keamanan pangan merupakan faktor yang penting dalam menjamin pangan yang aman untuk dikonsumsi. Salah satu kontaminasi yang menjadi masalah dalam keamanan pangan adalah kontaminasi kimia. Rajaganapathy et al. (2011) menyatakan toksisitas logam pada manusia dapat menyebabkan timbulnya kerusakan jaringan detoksikasi dan ekskresi (hati dan ginjal). Berdasarkan SNI no. 7387 tahun 2009 tentang batas maksimum kontaminasilogam berat dalam pangan, batas maksimum $\mathrm{Pb}$ adalah $1 \mathrm{mg} / \mathrm{kg}$, Cd sebesar $0,3 \mathrm{mg} / \mathrm{kg}$, dan $\mathrm{Cu}$ sebesar $5 \mathrm{mg} / \mathrm{kg}$ dalam bahan pangan. Menurut Agustina (2010) kontaminasi oleh logam berat, pestisida, asap kendaraan bermotor merupakan faktor utama penyebab kontaminasi logam berat.

Jumlah penjual yang dijadikan sampel pada penelitian ini adalah 3 dari 5 penjual di Bogor Utara. Penjual menjual ayam kuning sukabumi dengan jarak 1-3 meter dari jalan raya. Hal ini yang menyebabkan adanya kemungkinan terkontaminasinya ayam kuning sukabumi oleh udara yang mengandung logam berat.

Produk ayam kuning sukabumi dijual ke konsumen dengan menggunakan gerobak sebagai display dan alat transportasinya. Produk disimpan dalam panci dan ditutup dengan kain kasa untuk mencegah kontaminasi dari luar.

Penelitian ini bertujuan menganalisis 
pengaruh lama penjualan terhadap kadar kontaminasi logam berat timbal $(\mathrm{Pb})$, cadmium $(\mathrm{Cd})$ dan tembaga $(\mathrm{Cu})$ pada ayam kuning sukabumi di Kecamatan Bogor Utara.

\section{METODE}

\section{Materi}

Materi yang digunakan adalah 10 sampel ayam kuning sukabumi yang didapat dari lima penjual yang berbeda dan satu sampel karkas ayam (kontrol). Pengambilan sampel dilakukan dua kali dalam sehari, yakni 0 jam setelah penjualan dan 3 jam setelah penjualan. Materi kimia yang digunakan adalah bahan kimia untuk preparasi contoh dan pengujian dengan AAS.

\section{Preparasi Contoh (Milestone, 2010)}

Masing-masing ditimbang 0,5 gram sampel daging ayam kuning sukabumi dan daging ayam sebagai kontrol negatif. Sebanyak $8 \mathrm{~mL}$ larutan asam nitrat $\left(\mathrm{HNO}_{3}\right)$ $65 \%$ dan larutan asam hidrogen peroksida $\left(\mathrm{H}_{2} \mathrm{O}_{2}\right) 30 \%$ sebanyak $2 \mathrm{~mL}$ dimasukkan dalam tabung vessel. Destruksi basah dilakukan dengan memasukkan tabung-tabung vessel ke dalam Microwave Acid Digestion Apparatus. Setelah destruksi selesai tabung vessel harus mencapai suhu $40{ }^{\circ} \mathrm{C}$ agar dapat dibuka secara aman. Penambahkan deionized water hingga batas tera merupakan tahap terakhir dari persiapan sampel.

Pengukuran dilakukan dengan menggunakan Atomic Absorption Spectroscopy (AAS) Agilent Technologies 200 series AA flame type.

\section{Rancangan Percobaan}

Rancangan acak kelompok (RAK) merupakan rancangan yang digunakan pada penelitian ini.Perlakuan yang dilihat adalah waktu pengambilan sampel, dua taraf yakni 0 jam dan 3 jam dengan lima kelompok (kelompok berdasarkan jumlah penjual ayam kuning sukabumi) yang berada di Kecamatan Bogor Utara. Peubah yang diamati adalah kadar logam berat $\mathrm{Pb}, \mathrm{Cd}$, dan $\mathrm{Cu}$. Model matematika rancangan tersebut menurut Steel dan Torrie (1995) adalah:

$$
\mathrm{Y}_{\mathrm{ij}}=\mu+\alpha_{\mathrm{i}}+\beta_{\mathrm{j}}+\varepsilon_{\mathrm{ij}}
$$

Keterangan:

$\mathrm{Y}_{\mathrm{ij}}=$ nilai pengamatan dari waktu pengambilan sampel ke-i dalam kelompok ke-j

$\mu=$ nilai tengah umum

$\alpha_{i}=$ pengaruh perlakuan waktu pengambilan sampel ke-i

$\beta_{\mathrm{j}}=$ pengaruh kelompok penjual ayam kuning sukabumi ke-j

$\varepsilon_{\mathrm{ij}}=$ pengaruh galat perlakuan waktu pengambilan sampel ke-i dan kelompok penjual ayam kuning sukabumi ke-j

Analisis data selanjutnya diuji dengan analisis sidik ragam (ANOVA) pada $\alpha=0.05$.

\section{HASIL DAN PEMBAHASAN}

Identifikasi Kontaminasi Timbal (Pb), Kadmium (Cd), dan Tembaga $(\mathrm{Cu})$ pada Karkas Ayam

Kadar Cd pada karkas ayam sebelum diolah $0,46 \mathrm{mg} / \mathrm{kg}$, nilai ini di atas nilai SNI 7387:2009 yaitu $0,3 \mathrm{mg} / \mathrm{kg}$ (Tabel 1). Kadar $\mathrm{Cu}$ karkas ayam sebelum diolah $0,85 \mathrm{mg} / \mathrm{kg}$, nilai ini di bawah standar yang ditetapkan oleh Dirjen Pengawasan Obat dan Makanan Republik Indonesia, yaitu maksimal $5 \mathrm{mg} /$ kg. Rataan kadar $\mathrm{Pb}$ karkas ayam sebesar $0.76 \mathrm{mg} / \mathrm{kg}$, nilai ini di bawah ketentuan SNI 7387:2009 sebesar $1 \mathrm{mg} / \mathrm{kg}$.

Menurut Sudarmadji et al. (2006) kontaminasi logam $\mathrm{Cd}$ didapatkan dari kontaminasi knalpot sehingga nilai $\mathrm{Cd}$ lebih tinggi dibandingkan $\mathrm{Cu}$ dan $\mathrm{Pb}$. Ping et al. (2009) melakukan penelitian untuk melihat biotransfer logam berat dari tanah, tanaman, dan serangga pada rantai makanan. Terjadi penurunan konsentrasi logam berat dari tanah, ke tanaman dan menurun lagi pada serangga pada sistem rantai makanan. Pada penelitian tersebut disimpulkan logam berat $(\mathrm{Pb}$ dan Cd) lebih banyak terakumulasi pada akar dibandingkan pada tunas tanaman Rumex K-1. Pada penelitian ini juga diukur logam 
Tabel 1. Kadar logam berat karkas ayam sebelum diolah (ppm)

\begin{tabular}{lcc}
\hline Logam Berat & Konsentrasi & Batas Maksimum Cemaran \\
\hline Timbal $(\mathrm{Pb})$ & $0,76 \pm 0,14$ & 1,0 \\
Kadmium $(\mathrm{Cd})$ & $0,46 \pm 0,05$ & 0,3 \\
Tembaga $(\mathrm{Cu})$ & $0,85 \pm 0,01$ & 5,0 \\
\hline
\end{tabular}

berat pada karkas yang diberi pakan berupa tanaman (Rumex K-1) yang mengandung logam berat. Hasil penelitian menunjukkan konsentrasi logam berat pada hati, otot dan darah sangatlah bervariasi, konsentrasi tertinggi terdapat pada hati ayam dan terendah pada darah ayam. Akumulasi logam berat pada organ yang spesifik tidak dapat dihindarkan jika pakan yang dikonsumsi juga mengandung logam berat.

Sumber utama kontaminasi logam berat pada daging ayam dan daging kalkun berasal dari pakan ternak, air minum, lingkungan peternakan, selama proses penanganan dan pengemasan. Iwegbue et al. (2008) meneliti rata-rata kadar logam berat pada daging ayam, chicken gizzard dan daging kalkun adalah 4,95 - 48,23 ppm untuk $\mathrm{Cu}, 0,01-4,6$ ppm untuk $\mathrm{Cd}$ dan 0,01-3,43 ppm untuk $\mathrm{Pb}$. Nilai-nilai tersebut di atas standar yang telah ditetapkan oleh SNI (2009).

\section{Kontaminasi Timbal (Pb), Kadmium (Cd), dan Tembaga (Cu)}

\section{Kontaminasi Timbal (Pb)}

Pengujian kadar logam $\mathrm{Pb}$ ayam kuning sukabumi dapat dilihat pada Tabel 2. Hasil menunjukkan bahwa terjadi peningkatan nilai rataan kadar $\mathrm{Pb}$ sebesar $112 \%$ akibat lama penjualan selama tiga jam. Nilai ini di atas batas maksimum kontaminasi $\mathrm{Pb}$, kontaminasi maksimal Pb menurut SNI 7387:2009 sebesar $1 \mathrm{ppm}$. Perbedaan lamanya sampel terpapar di pinggir jalan berpengaruh secara nyata $(\mathrm{P}<0,05)$ terhadap kadar logam $\mathrm{Pb}$. Menurut Gustina (2012) logam timbal $(\mathrm{Pb})$ berada dalam kendaraan bermotor sebesar 25\%, 75 $\%$ berada di udara sebagai pencemar. Logam $\mathrm{Pb}$ diserap dan disimpan dalam darah.

Berdasarkan penelitian Nuryani et al. (2017) proses pengolahan dan distribusi tepung pada makanan gorengan atau pangan yang lain juga dapat menjadi jalan masuknya kontaminasi $\mathrm{Pb}$. Kadar $\mathrm{Pb}$ makanan gorengan setelah di jual naik $0,05 \mathrm{mg} / \mathrm{kg}$ dibandingkan sebelum digoreng dan di jual. Makanan gorengan yang di jual di pinggir jalan selama 2 jam meningkatkan $0,1193 \mathrm{mg} / \mathrm{kg} \mathrm{Pb}$.

Wagiu dan Wulur (2006) meneliti kadar $\mathrm{Pb}$ di pasar 45 Menado, didapatkan kadar $\mathrm{Pb}$ sebesar $0,799 \mathrm{mg} / \mathrm{m} 3$. Pengukuran kadar $\mathrm{Pb}$ dilakukan dalam tiga periode pendek dengan tiga waktu yang berbeda. Pada penelitian ini juga diukur kadar $\mathrm{Pb}$ di tempat lain dengan kondisi lingkungan di pinggiran kota , kesibukan transportasi yang kurang serta tidak terdapat terminal dan masih banyak pohon untuk penghijauan. Nilai kadar $\mathrm{Pb}$ di tempat tersebut adalah $0,273 \mathrm{ug} / \mathrm{m} 3$. Kedua hasil tersebut menunjukkan semakin tinggi kesibukan transportasi serta kurangnya pohon menghasilkan nilai $\mathrm{Pb}$ yang lebih tinggi. Kedua kadar $\mathrm{Pb}$ tersebut masih di bawah baku mutu WHO, yaitu $1 \mathrm{ug} / \mathrm{m} 3$ atau EPA 1,5 ug/ m3 menurut PP no. 41 tahun 1999.

Berdasarkan hasil penelitian menunjukkan terjadi peningkatan nilai rataan kadar $\mathrm{Pb}$ sebesar $112 \%$ akibat lama penjualan selama tiga jam. Hasil ini sejalan dengan hasil riset Wei and Yang (2010). Menurut Wei and Yang (2010) nilai kontaminasi $\mathrm{Pb}$ pada debu jalan di beberapa kota di Cina berada pada kisaran $26-408,41 \mathrm{mg} / \mathrm{kg}$. Nilai kontaminasiPb sebesar 17,98 - 25380,55 mg/ kg pada tanah di perkotaan Cina. Pada tanah pertanian di Cina juga ditemukan kontaminasi $\mathrm{Pb}$ yang berkisar $17,11-77,27 \mathrm{mg} / \mathrm{kg}$. Nilai kontaminasi $\mathrm{Pb}$ di tanah pertanian jauh lebih kecil dibandingkan pada debu dan tanah di perkotaan.

Okeye et al. (2011) melakukan penelitian terhadap konsentrasi logam berat 
Tabel 2. Nilai rataan kadar $\mathrm{Pb}, \mathrm{Cd}$ dan $\mathrm{Cu}$ ayam kuning sukabumi 0 jam penjualan dan setelah 3 jam penjualan (ppm)

\begin{tabular}{clcc}
\hline No & Logam Berat & 0 jam penjualan & 3 jam penjualan \\
\hline 1. & Logam $\mathrm{Pb}(\mathrm{ppm})$ & $2,26 \pm 1,03^{\mathrm{a}}$ & $4,81 \pm 1,58^{\mathrm{b}}$ \\
2. & Logam $\mathrm{Cu}(\mathrm{ppm})$ & $0,76 \pm 0,22^{\mathrm{a}}$ & $1,18 \pm 0,12^{\mathrm{b}}$ \\
3. & Logam $\mathrm{Cd}(\mathrm{ppm})$ & $2,08 \pm 0,48$ & $2,03 \pm 0,23$ \\
\hline
\end{tabular}

Keterangan: Superskrip berbeda pada baris yang sama menunjukkan berbeda nyata $(\mathrm{P}<0,05)$; Menurut SNI 7387:2009 batas maksimal $\mathrm{Pb}$ adalah $1 \mathrm{ppm}$; Batas Maksimum Cemaran Cd adalah 0,3 ppm (SNI 7387:2009); Batas Maksimum Cemaran Cu adalah 5 ppm (Dirjen Pengawasan Obat dan Makanan Republik Indonesia)

pada beberapa bagian ayam lokal dan eksotik (Broiler, cockerel, layers dan lokal) di kota Nsukka dan Enugu Nigeria. Logam berat didapatkan dari pembakaran bahan bakar fosil, penggunaan pupuk anorganik, kotoran hewan dan agrokimia. Pada penelitian ini disimpulkan bagian yang paling banyak mengandung $\mathrm{Pb}$ adalah hati, sedangkan persentase terbesar $\mathrm{Pb}$ terdapat pada ayam Cockerel. Kontribusi pakan terhadap logam berat pada ayam sangat rendah, kontribusi kontaminasi logam berat terbesar didapatkan dari polusi udara yang berasal dari pembakaran bahan bakar fossil.

\section{Kontaminasi Kadmium (Cd)}

Lama penjualan yeng berbeda berpengaruh nyata $(p<0.05)$ terhadap nilai logam $\mathrm{Cd}$ (Tabel 2). Kadar logam Cd mengalami peningkatan sebesar $55 \%$ akibat lama penjualan selama tiga jam dibandingkan dengan 0 jam. Nilai tersebut di atas nilai maksimum kontaminasi yang ditetapkan 0.3 ppm menurut SNI 7387:2009. Asap kendaraan bermotor menurut Sudarmadji et al. (2006) merupakan penyebab tingginya kadar logam $\mathrm{Cd}$.

Indeks kontaminasi logam berat di udara berhubungan erat dengan kontaminasi logam berat di sumber air irigasi dan juga tanah pertanian. Air yang dipergunakan untuk irigasi di Cina telah tercemar oleh logam $\mathrm{Cr}$, $\mathrm{Cu}, \mathrm{Ni}, \mathrm{Pb}, \mathrm{Zn}$ dan $\mathrm{Cd}$. Nilai kontaminasi terhadap air irigasi masih aman menurut aturan SEPA dan WHO.

Menurut hasil review Reeves dan Chaney (2008) ketersediaan Cd dalam makanan menyebabkan racun dalam tubuh.
Ketersediaan mineral essensial seperti $\mathrm{Zn}$ (Zink), $\mathrm{Fe}$ (besi), dan $\mathrm{Ca}$ (kalsium) berhubungan erat dengan ketersediaan $\mathrm{Cd}$ pada hewan percobaan. Penurunan ketersediaan ketiga mineral di atas akan meningkatkan akumulasi dan retensi $\mathrm{Cd}$ pada hewan percobaan.

Berdasarkan penelitian Puspita et al. (2010) nilai Cd pada tanaman kangkung yang berada pada aliran sungai bengawan solo tercemar oleh logam berat yang disebabkan oleh industri yang ada di sekitarnya. Nilai Cd pada sedimen sebesar $1,1925 \mathrm{ppm}$ dan nilai Cd pada tanaman kangkung sebesar 0,3217 ppm. Nilai tersebut di atas batas maksimum kontaminasi yang ditetapkan SNI 7387:2009 sebesar $0.3 \mathrm{mg} / \mathrm{kg}$.

\section{Kontaminasi Tembaga (Cu)}

Berdasarkan anova hasil penelitian menunjukkan rataan kadar $\mathrm{Cu}$ tidak dipengaruhi secara nyata oleh lama penjualan (Tabel 2). Nilai logam $\mathrm{Cu}$ masih di bawah batas maskimal menurut SNI 7387:2009 sebesar $0,5 \mathrm{mg} / \mathrm{kg}$.

Sharma et al. (2008) mengungkapkan aktivitas urban akan berkontribusi secara signifikan untuk menaikkan logam berat di atmosfer dan akan meningkatkan konsentrasi logam berat dalam sayuran. Untuk mengurangi resiko terhadap logam berat, sayuran sebaiknya dicuci terlebih dulu sebelum diolah lebih lanjut.

Menurut Duruite et al. (2007) beberapa logam berat diperlukan dalam industri, misalnya lampu merkuri, termometer $(\mathrm{Hg})$ sehingga pekerja yang terkait dengan 
industri tersebut akan lebih beresiko terkena kontaminasi logam berat tersebut. Efek negetif biotoksik tidak dapat dihindarkan, akan tetapi dengan tindakan pencegahan dan produksi secara hygiene akan mencegah kontaminasi pekerja dari kontaminasi logam berat.

\section{KESIMPULAN}

Lama penjualan 3 jam mempengaruhi nilai logam $\mathrm{Pb}$ dan $\mathrm{Cd}$ ayam kuning sukabumi. Nilai yang didapatkan melewati batas maksimal yang diperbolehkan. Nilai logam $\mathrm{Cu}$ tidak dipengaruhi oleh lama penjualan. Nilai yang didapatkan tidak melewati batas maksimal yang diperbolehkan.

\section{UCAPAN TERIMAKASIH}

Ucapan terimakasih disampaikan ke Balai Pengujian Mutu Produk Peternakan Bogor atas bantuan analisis sampel.

\section{DAFTAR PUSTAKA}

Agustina, T. 2010. Kontaminasi logam berat pada makanan dan dampaknya pada kesehatan. Teknubuga 2(2): 53-65.

[BSN] Badan Standardisasi Nasional. 2009. SNI 7387:2009: Batas Maksimum KontaminasiLogam Berat dalam Pangan Jakarta (ID): Badan Standardisasi Nasional.

Duruite, J.O., M.O.C. Ogwuegbu, and J. N. Egwurugwu. 2007. Heavy metal pollution and human biotoxic effects. International Journal of physical sciences 2(5): 112-118.

Gustina, D. 2012. Penkontaminasilogam berat timbal $(\mathrm{Pb})$ di udara dan upaya penghapusan bensin bertimbal. Berita Dirgantara volume 13 no. 3 : 95-101.

Iwegbue, C. M. A., G. E. Nwajei, and E. H. Iyoha. 2008. Heavy metals residues of chicken mea, gizzard, and turkey meat consumed in Southern Nigeria. Bulgarian journal of Veterinery Medicine 11(4): 275-280

Milestone. 2010. Pro-16 and pro-24 rotors user manual for wet destruction on AAS/ICP sample Rev. 7. Sorisole Italy.

Nuryani, R., E. Ismai dan T. Sari. 2017. Tinjauan keamanan pangan makanan gorengan berdasarkan cemaran kimia yang dijual di sepanjang jalan Kaliurang Sleman Yogyakarta. Jurnal Nutrisia 19(2): 113-118.

Okeye, C. O. B., A. U. Anneke., C. N. Ibeto, and J. N. hediona. 2011. Heavy metals analysis of local and exotic poultry meat. International Journal of applied environmental sciences 6(1): 49-55.

Ping, Z., Z. Huiling, and S. Whenseng. 2009. Biotransfer of heavy metals along a soil plant-insect-chicken-food chain : field study. Journal of Environmental Sciences 21: 849-853.

Puspita, A. R., R. Melannisa, dan A. Suhendi. 2010. Penetapan kadar logam $\mathrm{Pb}$ dan $\mathrm{Cd}$ dalam sedimen dan tanaman kangkung (Ipomoea aquatica) di sekitar sungai Bengawan Solo di kawasan industri Karanganyar. Pharmacon 11(2): 39-42..

Rajaganapathy, V., F. Xavier., D. Sreekumar, and P. K. Mandal. 2011. Heavy metal contamination in soil, water, fooder and their presence in livestock and products: a review. Journal of environmental science and technology 4(3): 234-249.

Reeves, P. and R. L. Chaney. 2008. Bioavailability as an issue in risk assessment and management of food cadmium: a review. Science of the Total Environment.

Sharma, R. K., M. Agrawal, and F. M. Marshall. 2008. Heavy metal (Cu, Zn. $\mathrm{Cd}$ and $\mathrm{Pb}$ ) contamination of vegetables in urban India: a case study in Varanasi. Environmental Pollution 154: 254-263.

Steel, R. G. D. and J. H. Torrie. 1995. Principles and Procedures of Statistics: 
A Biometrical Approach. Sumantri B, Penerjemah. Jakarta (ID): Penerbit PT. Gramedia Pustaka Utama.

Sudarmadji., J. Mukono, dan I. P. Corie. 2006. Toksikologi logam berat B3 dan dampaknya terhadap kesehatan. J. Kesehatan Lingkungan 2(2): 129-142.

Wagiu, A. F. dan F. H. Wulur. 2006. Hubungan antara kadar timbal udara dengan kadar timbal darah serta dampaknya pada anak. Sari Pediatri 8(3): 238-243.

Wei, B. and L. Yang. 2010. Review article : A review of heavy metal contamination in urban soils, urban road dusts and agricultural soils from China. Microchemical Journal 94: 99-107. 